San Jose State University

SJSU ScholarWorks

Master's Projects

Master's Theses and Graduate Research

$5-1-2006$

\title{
The Influence of Staff Nurse Ethnicity on Perceptions of the Work Environment
}

Silvia Helena Martins

San Jose State University

Follow this and additional works at: https://scholarworks.sjsu.edu/etd_projects

Part of the Other Nursing Commons

\section{Recommended Citation}

Martins, Silvia Helena, "The Influence of Staff Nurse Ethnicity on Perceptions of the Work Environment" (2006). Master's Projects. 788.

DOI: https://doi.org/10.31979/etd.d4tu-759z

https://scholarworks.sjsu.edu/etd_projects/788

This Master's Project is brought to you for free and open access by the Master's Theses and Graduate Research at SJSU ScholarWorks. It has been accepted for inclusion in Master's Projects by an authorized administrator of SJSU ScholarWorks. For more information, please contact scholarworks@sjsu.edu. 
SAN JOSE STATE UNIVERSITY

SCHOOL OF NURSING
SCHOOL. OF NURSING

JIIN $\cap 52006$

SAN SOS L UIATE UNIVERSTTY

\section{MASTER'S PROGRAM PROJECT OPTION (PLAN B)}

PROJECT SIGNATURE FORM
STUDENT NAME
Silvia Helena Maia Martins

SEMESTER ENROLLED

TITLE OF PROJECT

The Influence of Ethnicily on Staff Nurse Pereeptions of the work Environment

\section{NAME OF JOURNAL Journal of Nursing Care Quality}

The project and manuscript have been successfully completed and meet the standards of the School of Nursing at San Jose State University. The project demonstrates the application of professional knowledge, clinical expertise, and scholarly thinking. An abstract of the project and two copies of the manuscript are attached.

Chav olettil

ADVISOR'S SIGNATURE

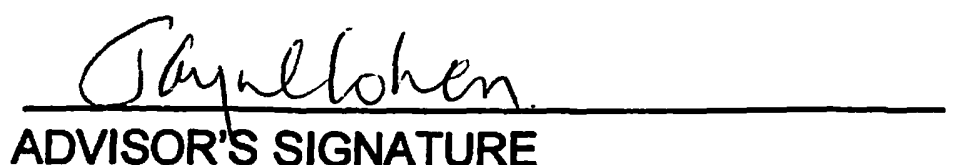

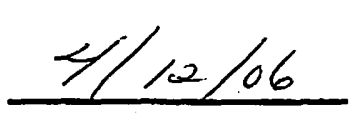

DATE

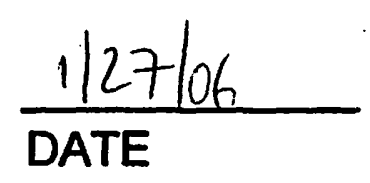

Please submit this form to the Graduate Coordinator. Attach abstract, two copies of the manuscript, and documentation of submission to the journal (i.e., postal receipt). 
AT\&T Yahoo! Mail

atet IAITOOI

MAIL
Welcome,

[Sign Out, My Account]
Search

the Web

Search

Mail Home I Tutorials I Help

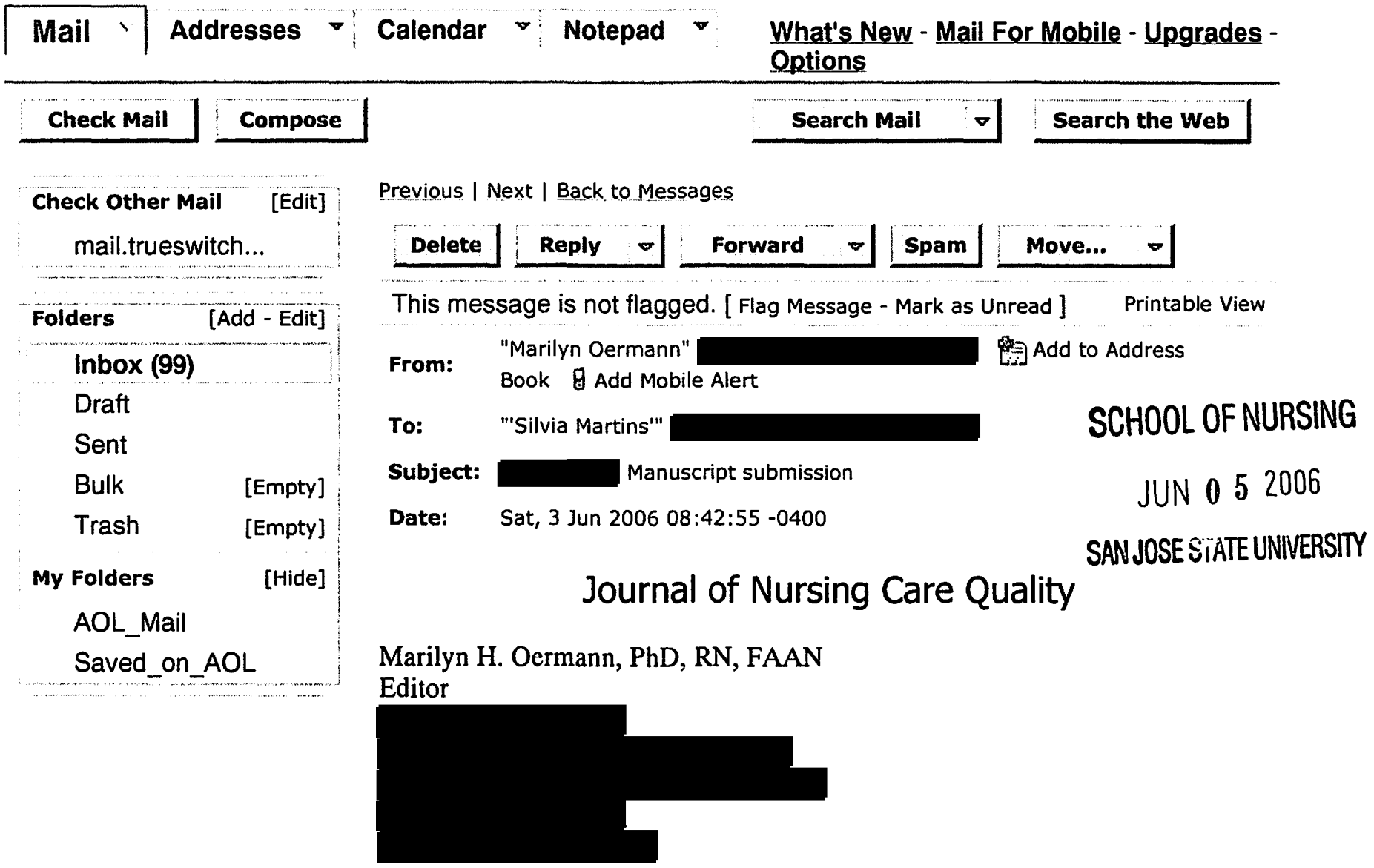

June 3, 2006

Ms. Silvia Helena Maia Martins, MS, RN

Staff Nurse II

The Permanente Medical Group

Santa Clara California

Dear Ms. Martins:

Your manuscript The Influence of Staff Nurse Ethnicity on Perceptions of the Work Environment has been received in the editorial office of the Journal of Nursing Care Quality. The review process will take approximately eight weeks. If you have any questions about the status of your review, please feel free to contact me.

Sincerely, Marilyn Oermann, PhD, RN, FAAN Editor 
THE WORK ENVIRONMENT

Silvia Helena Maia Martins, MS, RN

Staff Nurse II

The Permanente Medical Group

Santa Clara California

Diane L. Stuenkel, EdD, RN

Associate Professor

San Jose State University

School of Nursing

San Jose, California

Jayne Cohen, DNSc, RNC

Professor and Director

San Jose State University

School of Nursing

San Jose, California 
ABSTRACT

This study investigated the relationship among Registered Nurses (RNs) from different ethnic groups and their perceptions of the work environment in a community hospital in California. Moos' Work Environment Scale (WES) was used to examine three Dimensions of the work climate. Statistically significant differences were found in the way Caucasian and non-Caucasian RNs perceived Peer Cohesion and Work Pressure. These findings have implications for nurse leaders interested in transforming the work environment as perceptions of Peer Cohesion and Work Pressure are important factors influencing RN retention and quality of patient care.

Key words: work environment, work pressure, peer cohesion, ethnicity, nursing 
The shortage of professional nurses remains a serious problem in the United States (US). Registered Nurses' (RNs) employment increased 5.1\% from 2001 to 2002, representing an increase of over $100,000 \mathrm{RNs}$ into the US job market. 1 Hospital efforts to attract RNs initially focused on recruitment strategies. 2 These efforts resulted in a very large infusion of married, older, and foreign-born RNs, into the workforce. 1, 3 Many of these RNs were attracted by increased wages, a declining national economy that affected salaries of nurses' spouses, and private sector initiatives calling attention to the nursing shortage. 1 Despite this influx, the current nursing shortage could be intensified by the projected growth of the US population, the increase of the population age sixtyfive and older, and the aging of the nursing workforce. 4,5

Whereas there are many initiatives aimed at the recruitment of RNs, which may curb the nursing shortage, retention of RNs is also a challenge for nursing administrators. It is estimated that $15 \%$ of RNs change employment every year. 6 Total turnover costs per RN range from $\$ 62,100$ to $\$ 67,100$, representing costs associated with vacancy, including advertising and recruiting, orientation, training, and lower productivity levels of newly hired RNs. 7 In order to develop and implement strategies to promote the retention of RNs in the workforce, nurse leaders are encouraged to examine personal, job, and organizational factors that influence nurses' performance, and correlate these findings with organizational and patient care outcomes. 8

Because of its large health care system and increasing wages, the US is attractive to foreign nurses. Between 1996 and 2000, the number of foreign born RNs increased 35\%, and in the Pacific Coast area of the US, this group of nurses represented $21 \%$ of the workforce. 9 Over the last 50 years, the US has regularly recruited RNs from other 
countries to ease nursing shortages. 4 Given the likelihood of a persistent shortage of professional nurses, this strategy is one viable solution to the problem, although it poses an ethical dilemma.

Retaining nurses and creating a synergistic environment that integrates members of a multigenerational and ethnically diverse work force are major responsibilities of nursing managers. 10,11, 12 Formella and Rovin, 13 called for a redesign of the work environment, and Stuenkel, Cohen and de la Cuesta 11 further elaborated on the nurse manager's role. Nurse managers may influence retention by creating an environment of trust and support. In addition, the Joint Commission on Accreditation of Health Care Organizations (JCAHO) recommended that hospitals foster the creation of environments that attract, retain, empower, and add diversity to the nursing workforce. 5 Before changes can be made to the environment, however, it is necessary to assess how RNs perceive their work environment.

Despite a growing influx of ethnically diverse professional nurses in the US, very little research has been done in this area. There are approximately 133,041 Black (nonHispanic) nurses, 54,861 Hispanic/Latino nurses, 93,415 Asian/Pacific Islander nurses, and 13,040 American Indian/Alaska Native nurses in the US. 9 Diversity, according to Formella and Rovin, makes dialogue necessary. 14 To successfully incorporate new members into a team of professionals it is essential to listen and involve the new members into the redesign of the work environment. This study examined the relationship between the perceptions of work environment and nurses' ethnic background in a community hospital in California. 


\section{LITERATURE REVIEW}

Differences in perceptions of the work environment among multi-ethnic staff nurses were identified in a study in a large acute care hospital in California. Staten, Mangalindan, Saylor and Stuenkel found statistically significant differences for clarity of roles, managerial control, and the perceived degree of emphasis on innovation between Caucasian and non-Caucasian staff nurses.12 Of all the ethnic groups represented, Hispanic nurses were reported to perceive more managerial control, or the extent to which management uses rules and pressure to keep employees under control.

The work environment of freestanding hemodialysis facilities also has been studied. Thomas-Hawkins, Denno, Currier and Wick investigated the causes of a nursing shortage in a dialysis center by asking nurses to rate organizational characteristics found in their current work environment.15 Results of the study revealed that nurses perceived many favorable aspects of the work setting, such as interdisciplinary relationships, good working relationships with colleagues, safety of the environment, standardized policies and procedures, and respect for their nursing judgment. Unfavorable aspects were related to the amount of control over nurses' own practice. To decrease the shortage of professional nurses in dialysis centers, these authors suggested that factors encouraging retention should be clearly understood.

Moreover, an Australian study examined factors that motivated nurses to perform better and to stay in their jobs, as performance and retention affect patient care. Takase, Maude and Manias used the Person-Environment-Fit theory to investigate if the compatibility of nurses' work values and the perceptions of the environment could predict professional performance and intention to leave.16 The fit between the nurses' perception of the 
environment and their work values were not positively related to better performance. The findings indicated a statistically significant, positive correlation between negative perceptions of the environment and nursing turnover.

\section{CONCEPTUAL FRAMEWORK}

The work of Rudolf Moos provided the conceptual framework for this study. According to Moos, personal characteristics, the environment, coping, and adaptation are processes that can promote personal growth or decline. 17 Some people thrive when faced with adversity; others feel overwhelmed in mildly stressful environments. Personal characteristics develop and grow dependent upon the degree of openness and perceptions of the environment.

Work environments, as defined by Moos, have unique personalities capable of influencing and shaping the behavior of people who function in them. 18 These environments are affected by external and internal pressures, and include all the situations and conditions that define the work setting. In addition, work environments can be analyzed from three different perspectives: the human relations approach, the sociotechnical perspective, and a social information processing orientation. The human relations approach refers to associations between employees and supervisors; the sociotechnical perspective refers to the work employees perform and the organization of work groups; the social information processing orientation refers to employee's evaluation and appraisal of work related situations. 17

Moos described the association between the organizational system and work morale and performance, which are affected by the personal system and work stressors, as well as employees' coping responses. 17 Rarely, will a work environment meet all employees' 
needs. 19 However, the person-environment fit affects workers' performance, the outcomes of the organization, and quality of patient care. 20

\section{METHODOLOGY}

\section{Design}

An exploratory design was used to examine differences in staff RNs perceptions of the work environment among an ethnically diverse workforce.

\section{Sample and setting}

Participants were all acute care staff RNs recruited at a community hospital in California $(\mathrm{N}=744)$. The final sample consisted of 169 participants representing a questionnaire return rate of $23 \%$. The sample included all RNs who provided bedside care on all shifts, including charge nurses and assistant head nurses. Nurse managers, clinical nurse specialists, and staff development nurses were excluded.

\section{Research Instruments}

Two questionnaires were used. A demographic questionnaire solicited information such as gender, age, ethnic background, marital status, years in nursing, highest degree completed, length of time in present position, clinical level, hourly base rate, number of hours worked a week, and current enrollment in an academic program. The second instrument was Moos' Work Environment Scale (Form R) - WES. 21 The WES measured three major dimensions of the work environment: (a) Personal Growth/Goal Orientation, (b) Relationships and (c) System Maintenance/System Change. The tool consists of 90 true-or-false statements.

The Personal Growth/Goal Orientation Dimension focuses on independence, on getting the job done, and job demands. This dimension is divided into three subscales: 
(a) Autonomy measures the degree to which employees are encouraged to be selfsufficient, and to make their own decisions, (b) Task Orientation, measures the degree of emphasis on good planning, efficiency, and getting the job done, and (c) Work Pressure measures how much pressure and urgency dominates the work environment. 21

The Relationship Dimension focuses on employees' commitment to do their jobs, how friendly and supportive employees are to one another, and how supportive managers are. This dimension is divided into three subscales: (a) Involvement, measures how concerned and committed to their jobs employees are, how much pride they have in their work, and the effort they put into what they do, (b) Peer Cohesion, measures how friendly and supportive employees are to one another, and (c) Supervisor Support, measures the degree to which management is supportive of employees and encourages them to be supportive of one another. 21

The System Maintenance/System Change Dimension assesses the emphasis on rules, policies, variety and innovation in the work environment. It also taps into the pleasantness and comfort of the physical settings. There are four subscales in this dimension: (a) Clarity measures how clear and explicit rules and policies are communicated, (b) Control assesses the extent to which management uses rules and pressures to keep employees under control, (c) Innovation assesses the degree of emphasis on variety, change, and new approaches to do things, and (d) Physical Comfort, which measures the comfort in the physical place. 21

\section{Procedure}

After obtaining approval from the Institutional Review Board at the hospital and the - University, survey packets were hand delivered to nurse managers. Department managers 
assisted with distributing the packets during staff meetings and via employee mailboxes. The packets included: an overview of the study and an invitation to participate, a consent form, a Participant's Bill of Rights, the WES, the demographic questionnaire, and a $\$ 3.00$ coupon for a beverage at the hospital café. Participants were asked to sign the consent form and return the questionnaires to the researchers in a stamped, self-addressed envelope that was provided. Surveys were completed by the RNs on their own time, taking approximately 30 minutes. Only the researchers had access to the raw data, which were coded and kept locked in a secure location to insure confidentiality.

\section{Results}

Completed questionnaires were returned by 169 acute care RNs. The majority of the respondents were female (95.6\%), the largest age group was 50-59-year-olds (33.1\%), followed by $40-49$-year-olds (29.8\%). Most RNs had been in the nursing profession over 21 years (49.2\%), and had a baccalaureate degree in nursing $(52.5 \%)$. The largest ethnic group was Caucasian (71.3\%), followed by Filipino (12.2\%), Asian-non-Filipino (11\%), Hispanic (.6\%), African American (.6\%), and other-unknown (3.3\%). (Table 1)

The data were analyzed using descriptive and inferential statistics. The RNs in the sample were regrouped into 2 ethnic categories, Caucasians and non-Caucasians for analysis due to the small sample size of non-Caucasian groups. The $t$ test was used to examine the statistical significance of differences $(p \leq 0.5)$ in the mean scores for the 10 WES subscales between the two groups. Only the subscales of Peer Cohesion $(t=2.11, \mathrm{p}=.04)$ and Work Pressure $(t=2.25, \mathrm{p}=.03)$ showed a statistically significant difference between the means. (Table 2) 
The Peer Cohesion subscale (Relationship Dimension) of the WES assesses the extent that employees are perceived to be friendly and supportive of one another. Caucasian RNs reported higher perceptions of friendliness and support from coworkers $(M=6.6$, $\mathrm{SD}=2.0)$ than were reported by the non-Caucasian $\mathrm{RNs}(\mathrm{M}=5.9, \mathrm{SD}=1.9)$. The perceptions of Peer Cohesion were above average for Caucasians and average for nonCaucasians when compared to the norms established by Moos for the Health Care Work Group $(\mathrm{M}=5.2, \mathrm{SD}=2.0) .21$

The Work Pressure subscale (Personal Growth or Goal Orientation Dimension) assesses the degree to which work demands and time pressure dominate the work environment. 22 Caucasian nurses reported higher perceptions of Work Pressure $(M=5.8, S D=4.7)$ than non-Caucasian nurses $(M=4.7, S D=2.3)$. These means were compared to norms set by Moos for the Health Care Work Group $(\mathrm{M}=5.7, \mathrm{SD}=2.2)$, revealing above average perceptions of work pressure for Caucasians and average perception of Work Pressure by non-Caucasian nurses. 21

\section{DISCUSSION}

Findings suggest that perceptions of the work environment vary slightly between Caucasian and non-Caucasian RNs. Of the 10 subscales, only the Perceptions of Work Pressure and Peer Cohesion were statistically different for the sample. No statistically significant differences were identified for the subscales of Involvement, Supervisor Support, Autonomy, Task Orientation, Clarity, Control, Innovation, and Physical Comfort.

These findings are consistent with demographic factors. Most of the participants were between 40 and 59 years of age $(62.9 \%)$, had been registered nurses for 21 years or more 
(49.2\%), and had been in their present position for 21 years or more. These factors may account for a higher congruence with the environment. Nursing managers, however, cannot imply that changes are not necessary to improve the current work setting.

The results of this study support those of previous investigators. 11, 12 Ethnically diverse nurses perceive the work setting differently. Caucasian RNs perceived more Work Pressure than did the non-Caucasian group. This difference could be related to the setting in which they work, or could be related to demographic characteristics of the sample. Baby Boomers, which constituted the majority of the sample, are highly committed to work, and actively participate in activities in their units, which may increase the perception of Work Pressure. 11 Additionally, processes designed to deliver patient care should be carefully analyzed. Task requirements, workloads, organization policies, flexibility of schedule, staffing mix, and patient acuity are factors influencing job stress, job satisfaction and retention.

Shader and colleagues concluded that the more stress, the lower group cohesion and job satisfaction, and the higher the anticipated turnover. 22 The authors recommended that nurse managers remain cognizant of their workforce demographic characteristics. Years of experience, hours worked per week, distance from home to hospital, educational level, and job tenure are factors that influence the perception of Work Pressure. Managers need to know which factors affect their nurses' lives, as well as multigenerational work expectations and needs.

In addition to Work Pressure, Peer Cohesion was statistically significant. Caucasian RNs reported a higher degree of Peer Cohesion than that of non-Caucasian RNs. Good working relationships with colleagues have been reported in several studies $2,5,13,15$, as 
important factors determining RN's intentions to leave or stay in their present jobs, job satisfaction, and perceptions of the work environment.

The current study did not collect data on how long RNs had been in the US, nor how long the participants had worked together. DiMeglio and colleagues recommended nurse managers initiate conversations, and foster dialogues with staff to learn more about their values, traditions, expectations from work environments and supervisors. 23 The authors stated that team members become more cohesive when there is an effort to move beyond stereotypes, so that the focus is on similarities among the members, not differences. Strategies include holding focus groups with nurses to help determine which factors affect their staff. Using trained facilitators for debriefing after stressful situations can be an effective management strategy when dealing with a diverse workforce.

Other recommendations are using group exercises designed to determine personality types and communication styles among groups. The way people communicate with one another is an essential part of the process of team-building, and may prevent clashes between groups. Perceived negativism of individuals or groups, the ability to express frustration, and talk constructively can be learned during workshops in building communication skills. Building communication skills increases group cohesion.

The implications for nursing managers include understanding each individual on the unit, as well as differences in perceptions of the work setting among different ethnic groups. According to Ferris and colleagues, working with diverse groups may represent an opportunity to find new expertise. 24 In addition to valuing cultural differences, nurse administrators may also consider targeting interventions that are directed toward different ethnic groups. 
DiMeglio et al 23 suggested that each intervention designed to improve how groups work well together needs to be measured over time. Specific issues should be addressed to ensure that new RNs are a good "fit" both within the organization and on their specific unit. This issue however, should be approached with caution. A study by Takase and colleagues 16 revealed that the person-environment fit does not necessarily lead to better work performance.

\section{LIMITATIONS}

Limitations to the study relate to sample, size and setting. The sample size $(n=169)$ was small in proportion to the size of the nursing workforce. This was a convenience sample. Some of the ethnic groups had a very small response rate. Data were generated through a written self-report survey without any other comparative data in the same setting. Participants were required to sign the survey. All completed questionnaires were kept confidential, but anonymity could not be maintained. Therefore, responses may not be forthcoming and truthful, and may account for the low response rate. Participants in this facility may not reflect the same ethnic diversity as other facilities. Therefore, these findings should be generalized with caution.

\section{RECOMMENDATIONS}

This study adds to the growing body of knowledge about differences of perceptions of the work environment. There are few studies dedicated to exploring such differences, and the information is valuable to nurse managers. Nurse administrators might consider spending time on their units to examine the demographic characteristics of their nursing workforce, observe group's dynamics, and identify potential barriers to cohesive group functioning. 
The lack of research involving the potential influence of ethnicity among RNs in the work setting is a driving force for administrators to assess potential implications on their individual units. Transformational leaders, who truly want improved environments for the nursing workforce, will take information from surveys and their own observations, approach the nurses, and ask them if the data reflect their own views.

In the next 20 years approximately $50 \%$ of the workforce represented by this sample will be eligible for retirement. Registered nurses with a myriad of ethnicities will fill more of these vacant positions. Nurse managers will be responsible for incorporating these diverse RNs into their units. It is imperative for health care agencies to explore options and create alternatives geared toward retaining a diverse nursing workforce that reflects the ethnic mix of the communities served. 


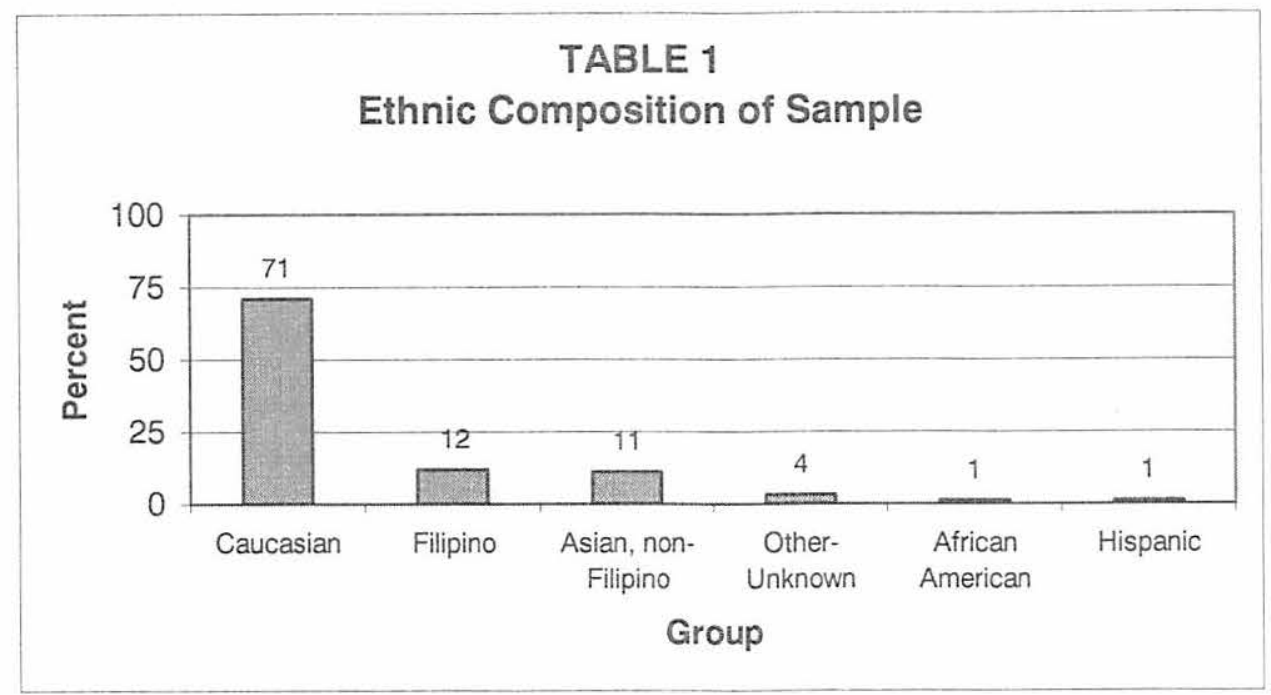

\begin{tabular}{|c|c|c|c|c|c|c|}
\hline \multirow[b]{3}{*}{ Scale } & \multirow{2}{*}{\multicolumn{2}{|c|}{ Caucasian $\mathrm{N}=129$}} & $\begin{array}{l}\text { TABLE } \\
\text { of WES } \\
\text { Ethnici }\end{array}$ & scal & & \multirow{3}{*}{$\frac{\text { Sig. (2- }}{\text { tailed) }}$} \\
\hline & & & \multicolumn{2}{|c|}{ Non-Caucasian $\mathrm{N}=40$} & \multirow[b]{2}{*}{$\underline{t}$} & \\
\hline & Mean & $\underline{\mathrm{SD}}$ & Mean & $\underline{S D}$ & & \\
\hline INVOLVEMENT & 7.1 & 2.1 & 6.8 & 1.9 & -0.897 & 0.371 \\
\hline PEER COHESION* & 6.6 & 2.1 & 5.9 & 1.8 & -2.108 & 0.037 \\
\hline SUPERVISOR SUPPORT & 6.1 & 2.1 & 5.7 & 2.1 & -1.178 & 0.24 \\
\hline AUTONOMY & 6.1 & 2 & 5.9 & 2 & -0.792 & 0.43 \\
\hline TASK ORIENTATION & 7.2 & 1.8 & 7.1 & 2 & -0.574 & 0.567 \\
\hline WORK PRESSURE** & 5.6 & 2.3 & 4.7 & 2.3 & -2.251 & 0.026 \\
\hline CLARITY & 5.9 & 1.6 & 5.6 & 2.3 & -1.187 & 0.237 \\
\hline CONTROL & 6 & 1.5 & 6.2 & 1.5 & 0.78 & 0.436 \\
\hline INNOVATION & 4.7 & 2.5 & 4.7 & 2.1 & -0.065 & 0.948 \\
\hline PHYSICAL COMFORT & 5 & 2.6 & 5.1 & 2.4 & 0.124 & 0.902 \\
\hline
\end{tabular}

${ }^{*} \mathrm{p} \leq .05$ 


\section{REFERENCES}

1. Buerhaus PI, Staiger DO, Aurbach DI. New signs of a strenghthening U.S. nurse labor market? Health Affairs. 2004;W4:526-533.

2. Ulrich BT, Buerhaus PI, Donelan K, Norman L, Dittus R. How RNs view the work environment. JONA. 2005;35:389-396.

3. Buerhaus PI, Staiger DO, Auerbach DI. Is the current shortage of hospital nurses ending? Health Affairs. 2003; 22:191-198.

4. Brush BL, Sochalski J, Berger AM. Imported care: Recruiting foreign nurses to U.S. health care facilities. Health Affairs. 2004; 23:78-87.

5. JCAHO Report, Aug. 7, 2002: Health care at the crossroads: Strategies for addressing the evolving nursing crisis. Maine Nurse. 2002; November 1; (4).

6. Survey: High nurse turnover equals high cost. (Nursing Workforce). (Feb 4, 2002) In Medicine \& Health, 56, p5(1). Retrieved January 18, 2006, from Health Reference Center Academic via Thomson Gale: http://0-find.galegroup.com. mill1.sjlibrary.org:80/ips/infomark.do?\&contentSet=IAC-

7. Jones, CB. The costs of nurse turnover, Part 2: Application of the nursing turnover cost calculation methodology. JONA. 2005;35:41-49.

8. McLennan M. Nurse's views on work enabling factors. JONA. 2005;35:311-318.

9. Minority Nursing Statistics. The registered nurse population: Findings from the National Sample Survey of Registered Nurses, March 2000. Available at: http://bhpr.hrsa.gov/healthworkforce/reports/rnsurvey/rnss1.htm. Accessed November 8, 2005.

10. Gage, M. From independence to interdependence: Creating synergistic healthcare 
teams. JONA. 1998;28:17-26.

11. Stuenkel DL, Cohen J, de la Cuesta, K. The multigenerational nursing workforce: essential differences in perceptions of work environment. JONA. 2005;35:283-285.

12. Staten DR, Mangalindan MA, Saylor CR, Stuenkel DL. Staff nurse perceptions of the work environment: A comparison among ethnic backgrounds. J Nurs Care Qual. 2003;18:202-208.

13. Formella N, Rovin S. Creating a desirable future for nursing, Part 2: The issues. JONA. 2004;34:264-267.

14. Rovin S, Formella N. Creating a desirable future for nursing, Part 1: The nursing shortage is a lack of creative and systemic thinking. JONA. 2004;34:163-166.

15. Thomas-Hawkins C, Denno M, Currier H, Wick G. Staff nurses' perceptions of the work environment in freestanding hemodialysis facilities. Nephrology Nursing Journal. 2003;30:377(11).

16. Takase M, Maude P, Manias E. Explainig nurses' work behaviour from their perception of the environment and work values. International Journal of Nursing Studies. 2005;42:889(10).

17. Moos RH. A social climate scale Work Environment Scale Manual. Development, Applications, and Research. $3^{\text {rd }}$ ed. Palo Alto, CA: Consulting Psychologists Press; 1994.

18. Moss RH. The Human Context - Environmental Determinants of Behavior. New York: Wiley; 1976.

19. Insel PM, Moos RH. The Social Environment. In: Insel PM, Moos RH, eds. Health and the Social Environment. Lexington: Heath: 1974:3-35. 
20. Moos RH. The mystery of human context and coping: An unraveling of clues. American Journal of Community Psychology. 2002; 30:67(22).

21.Moos RH, Insel PM. Work Environment Scale: Form R. Palo Alto, CA: Consulting Psychologists Press; 1994.

22.Shader K, Broome ME, Broome CD, West ME, Nash M. Factors influencing satisfaction and anticipated turnover for nurses in an Academic Medical Center. JONA. 2001;31:210-216.

23.DiMeglio K, Padula C, Piatek, C, et al. Group cohesion and nurse satisfaction. JONA. 2005;35:110-120.

24. Ferris GR, Frink DD, Bhawuk DPS, Zhou J, Gilmore DC. Reactions of diverse groups to politics in the workplace. Journal of Management. 1996; 22: p23(22). 